NASA Technical Memorandum 102018

\title{
The Low Frequency Oscillation in the Flow over a NACA0012 Airfoil With an "Iced" Leading Edge
}

(NASA-TH-102018) THE LCH FEECUERCY CSCILLATION IH TEE FLOH OVER IACAOO12 AIEFOIL WITH AN ICED LEADIAG LDGE (HASA. Leyis Research (enter) 16 f CSCL 01a

K.B.M.Q. Zaman and M.G. Potapczuk Lewis Research Center Cleveland, Ohio

Prepared for the Conference on Low Reynolds Number Aerodynamics sponsored by the University of Notre Dame Notre Dame, Indiana, June 5-7, 1989 
THE LOW FREQUENCY OSCILLATION IN THE FLOW OVER A NACAO012

AIRFOIL WITH AN "ICED" LEADING EDGE

K.B.M.Q. Zaman and M.G. Potapczuk

National Aeronautics and Space Administration

Lewis Research Center

Cleveland, Ohio 44135

\title{
Summary
}

The unusually low frequency oscillation in the wake of an airfoil, studied in [1], is explored experimentally as well as computationally for a NACA0012 airfoil with a "glaze ice accretion" at the leading edge. Experimentally, flow oscillations are observed at low frequencies that correspond to a Strouhal number of about 0.02 . This occurs in the angle of attack range of $8^{\circ}$ to $9^{\circ}$, near the onset of static stall for this airfoil. With a Navier-Stokes computation, "limit-cycle" oscillations in the flow and in the aerodynamic forces are also observed at low Strouhal numbers. However, the occurrence of the oscillation is found to depend on the turbulence model in use as well as the Reynolds number.

\author{
Nomenclature \\ c airfoil chord \\ $c_{1} \quad$ lift coefficient \\ $C_{d} \quad$ drag coefficient \\ $C_{m} \quad$ moment coefficient about $0.5 c$ \\ M Mach number \\ $f_{s} \quad$ shedding or oscillation frequency \\ $R_{C} \quad$ chord Reynolds number \\ St $\quad$ Strouhal number, $f_{S} c \sin \alpha / U_{\infty}$ \\ $u^{\prime}(f)$ one-dimensional, longitudinal velocity spectrum \\ $U_{\infty} \quad$ free-stream mean velocity \\ $\alpha \quad$ angle of attack
}




\section{Introduction}

An unusually low frequency oscillation in the flow over a LRN(1)-1007 airfoil was studied experimentally as well as computationally in [1], over the $R_{C}$ range of $15 \times 10^{3}$ to $300 \times 10^{3}$. The phenomenon involved a naturally occurring periodic switching between stall and unstall around the onset of the static stall condition. The frequency was considered low as the corresponding Strouhal number, based on the cross-stream length scale and the free stream velocity, was only about $0.02, a n$ order of magnitude lower than that experienced in the commonly observed bluff-body shedding (see also [2]). Even though the mechanism of frequency selection has remained unresolved, the measurements established that the phenomenon was indeed aerodynamic in origin. Any connection to a standing acoustic wave, structural resonance or unsteadiness associated with the tunnel was ruled out. The flow oscillations imparted very large unsteady forces to the airfoil. Thus, investigations leading to a clearer understanding of the phenomenon are well in order from the point of view of applications involving unsteady aerodynamic loads, e.g., in stall flutter of blades and wings.

In [1], unsteady oscillations were also observed computationally that had striking similarities with the experimental results. In an independent study [3], symptoms of the phenomenon were also encountered in a Navier-Stokes computation for the flow over a NACAOO12 airfoil with "glaze ice accretion." A glaze ice accretion develops during flight conditions just below the freezing temperature. These shapes are typified by large "horns" (see the simulated shape in Figure 1(b)). This led to a wind tunnel experiment with an airfoil model having the same crosssectional shape as used in [3]. Lift characteristics showed the onset of static stall around $\alpha \approx 7^{\circ}$ with this airfoil. Slightly above this $\alpha$, wake oscillations were observed resulting in an unambiguous peak in the velocity spectra, although not as sharp as in the "LRN" airfoil case, at a Strouhal number of about 0.02 !

The objective of the present paper is to summarize these results. Salient features of the phenomenon observed with the "LRN" airfoil are reviewed first. The experimental results obtained with the "iced" airfoil are then presented, followed by a discussion of limited computational results. As it will be observed, even though the computation seems to capture the essence of the phenomenon, the results vary widely depending on the turbulence model in use and the Reynolds number. 


\section{Experimental Procedure}

The experiments were carried out in a low speed wind tunnel which has been described in detail elsewhere [1,4]. Figure $l(a)$ is a photograph of the test section as set up during a somewhat similar experiment [4]. The test section is $76 \mathrm{~cm}$ (wide) by $51 \mathrm{~cm}$ (high). The maximum speed is about $16 \mathrm{~ms}^{-1}$, however, some of the data were obtained using a smaller drive motor yielding a maximum speed of about $10 \mathrm{~ms}^{-1}$. The free-stream turbulence intensity is less than 0.1 percent, but could be raised to about 0.4 percent by inserting a 30 -mesh screen about $21 \mathrm{~cm}$ upstream of the airfoil support. Two-dimensional airfoil models were used in the experiment. Data from the LRN(1)-1007 and a NACA0012 airfoil with simulated "glaze ice shape" at the leading edge are presented. Both are of nominal chord of $12.7 \mathrm{~cm}$ and of aspect ratio of about 6 . These two airfoils, whose cross sections are shown in Figure 1(b), are referred to simply as the "LRN" and the "iced" airfoils, respectively. The photograph in Figure $l(a)$ shows the "LRN" airfoil mounted in the tunnel.

Standard hot-wire anemometry was used for velocity measurements. A Nicolet 660B analyzer was used for spectrum analysis. There was provision for acoustic excitation of the flow, and an automated angular positioning device was used during the measurement of the lift and the drag [4]. The airfoils were supported at both ends at mid-chord. The coordinate origin is at the airfoil mid-chord and the axis of the test section. $x, y$ and $z$ denote streamwise, vertical and spanwise coordinates, respectively. The angle of incidence $\alpha$ is measured with respect to the (dashed) chord lines as shown in Figure $l(b)$.

\section{Results and Discussion}

3.1 Summary of results of [1]: Key results from [1], for the "LRN" airfoil, are shown in Figures 2 to 5 . The wake velocity spectra for different $\alpha$ are shown in Figure 2. At large a spectral peaks are observed at relatively higher frequencies which correspond to $S t_{s} \approx 0.2$. This is due to the familiar bluff-body shedding involving the asymmetric Kárman vortex street. Around the onset of static stall, however, at about $\alpha=15^{\circ}$ in this case, the low frequency oscillation is observed, the corresponding $s t_{s}$ being an order of magnitude lower. It is this low Sts oscillation -- its origin, significance as well as its contrast to the bluff-body shedding -- that has been addressed in [1].

The occurrence of the low sts oscillation was found to be rather illusive and sensitive to ambient conditions. This is delineated by the data in figures 3 
and 4. The lower pair of spectra in Figure 3 shows that with the normal tunnel operation yielding a turbulence intensity of about 0.1 percent, the periodic oscillation does not take place; however, it does when the free-stream turbulence is raised with the help of the screen inserted upstream of the test section. Note that the oscillation was observed previously in a Langley tunnel in which the freestream turbulence was also higher -- about 0.25 percent [2]. The upper pair of spectra in Figure 3 demonstrate that the low frequency oscillation can also be precipitated if acoustic excitation in a certain high frequency range is applied.

On the other hand, when the oscillation takes place naturally, e.g., in the flow with the higher free-stream turbulence, acoustic excitation in a relatively higher frequency range is found to eliminate it. An example is shown by the pair of spectra in Figure 4. The ranges of excitation frequency augmenting or suppressing the $S t_{s} \approx 0.02$ oscillation have been documented for various conditions in [1]. The higher frequency excitation producing the suppression effect shown in Figure 4 appears to involve "acoustic tripping" of the separating boundary layer. It is conjectured that the boundary layer around the region of separation is turned fully turbulent by the acoustic excitation -- in which case the low frequency oscillation does not take place. Thus, on the one hand the phenomenon does not seem to take place in clean flows yielding laminar boundary layers, while on the other, it also disappears when the separating boundary layer is fully turbulent. Therefore, a certain transitional state near the separation region seems to be a requisite for the low frequency oscillation to take place [1].

Also included in [1] are the computational results for the "LRN" airfoil. C.L. Rumsey had previously observed a similar low frequency oscillation computationally for a NACA0012 airfoil at $\alpha=18^{\circ}$ [5]. The computations were then carried out for the Reynolds number and airfoil shape as in the experiment. The results were found to capture the essential features of the experimental observation. The computed flow field agreed in overall features with corresponding measurements. The computed force fluctuations also agreed generally with the experimental results, as shown in Figure 5. Despite the difference in the Strouhal number, the amplitudes and the details of the fluctuations are found to have close similarities. Aspects of Rumsey's computation will be discussed further in the following.

3.2 Present experimental results: For comparison with the "iced" airfoil, the lift, drag and moment coefficient variation with a for the "LRN" airfoil are documented in Figure 6 . Note that the low frequency oscillation takes place around 
$15^{\circ}$ (within a narrow range of $\alpha$ ) where the forces and the moment go through a large change due to stall.

Corresponding aerodynamic data for the "iced" airfoil are shown in Figure 7. In comparison to the "LRN" airfoil, the stall occurred at a much lower angle of attack of about $7^{\circ}$. No hysteresis was observed around the stall angle. It is slightly above this $\alpha$ where this airfoil exhibited a similar low frequency oscillation.

Wake velocity spectra similar to those in Figure 2 are presented in figure 8 for the "iced" airfoil. The oscillation is observed to occur around the $\alpha$-range of $8^{\circ}$ to $9^{\circ}$. Note that in this case the spectral peak is not as sharp as in the "LRN" airfoil case, but the tendency towards an oscillation around $s t_{S}=0.02$ is unambiguous. The oscillation at three different Reynolds numbers at $\alpha=8.5^{\circ}$ is documented in Figure 9. $R_{C}=1.25 \times 10^{5}$ corresponds to the highest speed obtainable in the tunnel.

The effect of acoustic excitation on the low frequency oscillation over the "iced" airfoil was briefly studied in the present experiment. An attempt was made to augment the oscillation as in the "LRN" airfoil case (Figure 3). However, the spectral peak could not be made much sharper under the acoustic excitation.

Increasing the free-stream turbulence with the screen also did not make a significant difference. However, the suppression of the low frequency oscillation, as shown in Figure 4 for the "LRN" airfoil, could be achieved. An example is shown in Figure 10.

The data in Figures 7 to 10 lead us to believe that the oscillation taking place around $\alpha \approx 8.5^{\circ}$ with the "iced" airfoil is morphologically the same as that studied in [1]. The differences observed with respect to the effect of acoustic excitation are not surprising and reinforces the notion that the phenomenon is very sensitive to ambient perturbations affecting the state of the separating boundary layer.

It was observed in [1] that the phenomenon seems to occur with airfoils exhibiting "trailing edge stall" or "leading edge stall accompanied by a separation bubble", but not with ones exhibiting the "abrupt leading edge stall". The computations and experiments suggest that the "iced" airfoil belong to the second of the aforementioned stall categories (leading edge stall accompanied by a separation bubble), thus, corroborating the above observation. Note that the "LRN" airfoil is a borderline case between the first and the second categories of stall. An Wortman airfoil, on the other hand, is clearly characterized by the third category of stall, and thus, does not exhibit the low frequency oscillation [1]. 
3.3 Similar observations by others: It appears that the low frequency oscillation phenomenon has gone practically unrecognized over the several decades of airfoil research. To our knowledge, there are only a few references in the literature regarding similar observations. B.M. Jones (1934; see [1]) and Farren (1935; [6]) apparently encountered the phenomenon. Figure $11(a)$ reproduces the essential feature of Farren's data in this connection. Farren was actually developing a fast response balance and experimenting with oscillating airfoils. In his report, also included was the normal force variation with time for a R.A.F. 28 airfoil held fixed at $\alpha=14^{\circ}$. This airfoil was previously observed by B.M. Jones to undergo violent fluctuations near stalling conditions. The average period of oscillation (Figure $11(a)$ ) was observed by Farren to correspond to 13 chords of travel. This converts to $s t_{s}=0.019$.

At NASA Lewis there is a research program addressing the problem of airfoil leading edge ice accretion and its remedies. The program includes computation and experiments on the aerodynamic characteristics of such airfoil sections both in-house and under grants. Bragg and Khodadoust [7], under a grant, obtained wind tunnel data on the aerodynamic characteristics of a NACA0012 airfoil with simulated ice shapes. Recently, for a "glaze ice" shape, (same as in the present study), they also observed a low frequency flow oscillation. Figure 22 of their paper is reproduced as Figure 11(b). The data represent $u^{\prime}$-spectrum measured near the upper edge of the shear layer, shortly downstream of the "ice horn", for $\alpha \approx 6^{\circ}$. (Note that " $\alpha=4^{\circ}$ " quoted in their paper is measured with respect to the chord of the basic NACA0012 airfoil. $\alpha$, measured with respect to the chord as shown i.l Figure $1(b)$, is about $2^{\circ}$ larger). There is a clear peak in the spectrum, and this corresponds to $S t_{s} \approx 0.016$. The authors did not find such spectral peak at other locations over the airfoil and, therefore, commented that it should represent a local shedding from the ice horn and not a global bubble oscillation. However, their observations were preliminary, and it would appear that the same phenomenon, as addressed here, has been encountered by them. Their data, however, represent a significantly higher $R_{C}$ of $1.5 \times 10^{6}$, indicating that the phenomenon may not be characteristic of low Reynolds number airfoils only. Other relevant observations in the literature, including the characteristic frequencies in dynamic stall and stall flutter, have been discussed in [1].

3.4 Computational result: A two-dimensional Navier-Stokes code coupled with a $C$-mesh grid generation code was used for the computations, the details of which can be found in [3]. A "modified mixing length" (MML) turbulence model was used 
in the computation. An unsteady flow with "periodic vortex shedding" was noted around $\alpha=8^{\circ}$. The lift coefficient variation with time, computed for the same flow conditions of [3], is shown in Figure 12(a). Similarities can be observed with the $C_{1}$ variation for the "LRN" airfoil (Figure 5). However, when the Baldwin-Lomax turbulence model was used in the present computation the oscillations damped out in the resultant flow field. This is shown in Figure $12(b)$.

Here, let us note that in the computations by Rumsey that resulted in low frequency oscillation for the "LRN" airfoil (Figure 5), the Baldwin-Lomax turbulence model was used. Rumsey [5] also observed similar low frequency oscillations for a NACA0012 airfoil at $\alpha=18^{\circ}$ and $R_{C}=10^{6}$.

The algorithms used in [3] and [5] are basically similar. The "MML" is an algebraic turbulence model which attempts to avoid some of the difficulties encountered with Baldwin-Lomax turbulence model when applied to separated flows.

Details of the model will be discussed in the second author's dissertation, which is forthcoming. The "turbulent viscosity" $\left(\mu_{t}\right)$ obtained from the two turbulence models are quite different. Typically, the "MML" model obtains $\mu_{t} / \mu 1$ values on the order of $10^{3}$ while in a comparable flow the Baldwin-Lomax model obtains values on the order of $10^{4}$, where $\mu$ is the laminar viscosity. It is probable that the "transitional state" of the separating boundary layer, conjectured in [1] to be necessary to produce the low frequency oscillation, may be characterized by certain values of the ratio $\mu \mathrm{t} / \mu \mathrm{l}$. However, a systematic trend is far from clear at this point and will require further investigation.

The computations were also carried out for the "iced" airfoil, at $\alpha=9^{\circ}$, $R_{C}=10^{5}$ and $M=0.10$, to approximately match the present experimental conditions. The results have added further to the confusion. The "MML" turbulence model, which yielded the oscillation at the higher $R_{C}$, resulted in damped oscillations. The corresponding $C_{1}$ variation is shown in Figure 13(b). On the other hand, when the flow was assumed laminar for this case, the computation yielded a low frequency oscillation! This is shown in Figure 13(a). The $s_{s}$ values corresponding to the oscillations in Figures $12(a)$ and $13(a)$ turn out to be about 0.011 and 0.008 , respectively. Let us note, for comparison, that Rumsey's computation for both airfoils ("LRN" and NACA0012) yielded an $\mathrm{st}_{\mathrm{s}} \approx 0.03$. The experimental and the computational results are summarized in Tables 1 and 2 , respectively. 


\section{Concluding Remarks}

The experimental evidence gathered in this paper suggest that the low frequency oscillation may indeed be a frequent occurrence with various airfoils. Its occurrence with "glaze ice accretion" is certainly a possibility. Thus, the leading edge ice accretion may not only be detrimental for aerodynamic performance but should also be of concern in terms of large unsteady loads associated with the phenomenon. The phenomenon, however, occurs in a narrow range of angle of attack around the onset of static stall. The acoustic excitation effect results also suggest a possible remedy, which needs to be explored further. The accumulated experimental evidence points towards a strouhal number of about 0.02 associated with the phenomenon, although there are scatter in the data. With respect to the computations, questions remain in the application of turbulence models to separated

flows. Nevertheless, it is felt that the essence of the phenomenon can be captured computationally with certain combinations of turbulence model, Reynolds number and airfoil shape. Obviously, a detailed computational study is in order not only to explore the validity of the algorithms but also to shed light into the still unresolved mechanism of this curious phenomenon.

\section{References:}

[1] "A natural low frequency oscillation of the flow over an airfoil near stalling conditions", K.B.M.Q. Zaman, D.J. McKinzie and C.L. Rumsey, J. Fluid Mech., 202, pp. 403-442, 1989.

[2] "Effect of acoustic excitation on the flow over a low-Re airfoil", K.B.M.Q. Zaman, A. Bar-Sever and S. M. Mangalam, J. Fluid Mech., 182, pp. 127-148, 1987.

[3] "Numerical analysis of a NACA0012 airfoil with leading edge ice accretions", M.G. Potapczuk, AIAA Paper No. 87-0101, 1987.

[4] "Control of "Laminar Separation" over Airfoils by Acoustic Excitation", K.B.M.Q. Zaman and D.J. MCKinzie, AIAA Paper No. 89-0565, 1989.

[5] "A computational analysis of flow separation over five different airfoil geometries at high angles-of-attack", C.L. Rumsey, AIAA Paper No. 87-0188, 1987. 
[6] "The reaction on a wing whose angle of incidence is changing rapidly. Wind tunnel experiment with a short period recording balance", W.S. Farren, Report \& Memorandum 1648, Aeronautics Laboratory, Cambridge, 1935.

[7] "Experimental measurements in a large separation bubble due to a simulated glaze ice accretion", M.B. Bragg and A. Khodadoust, AIAA Paper No. 88-0116, 1988.

TABLE 1. - EXPERIMENTAL RESULTS ON THE LOW FREQUENCY OSCILLATION

\begin{tabular}{|c|c|c|c|c|c|}
\hline Airfoil & $\alpha$ & $\mathrm{R}_{\mathrm{C}} \times 10^{-3}$ & $\begin{array}{l}c, \\
c m\end{array}$ & $\mathrm{St}_{\mathrm{s}}$ & $\begin{array}{l}\text { Refer- } \\
\text { ence }\end{array}$ \\
\hline $\begin{array}{l}\text { R.A.F.28 } \\
\text { "LRN" } \\
\text { "LRN" } \\
\text { "LRN" } \\
\text { "LRN" } \\
\text { NACA0012 }\end{array}$ & $\begin{array}{l}14 \\
15 \\
17 \\
15 \\
16 \\
14\end{array}$ & $\begin{array}{c}100 \\
40 \text { to } 140 \\
15 \text { to } 25 \\
50 \text { to } 150 \\
100 \text { to } 300 \\
70\end{array}$ & $\begin{array}{r}15.2 \\
10.2 \\
7.3 \\
12.7 \\
25.4 \\
10.2\end{array}$ & $\begin{array}{l}0.019 \\
0.02 \\
0.025 \\
0.02 \\
0.033^{\dagger} \\
0.022\end{array}$ & $\begin{array}{l}{[6]} \\
{[2]} \\
{[1]} \\
{[1]} \\
{[1]} \\
{[1]}\end{array}$ \\
\hline $\begin{array}{l}\text { Wortman } \\
\text { "Iced" } \\
\text { "Iced" }\end{array}$ & $\begin{array}{l}15 \\
6 \\
8.5\end{array}$ & $\begin{array}{l}50 \text { to } 150 \\
1500 \\
75 \text { to } 125\end{array}$ & $\begin{array}{l}12.7 \\
55 \\
12.7\end{array}$ & $\begin{array}{l}\text { Damped } \\
0.016 \\
0.02\end{array}$ & $\begin{array}{c}{[1]} \\
{[7]} \\
\text { Present }\end{array}$ \\
\hline
\end{tabular}

tHigher mean velocity due to large blockage may have resulted in higher $\mathrm{St}_{\mathrm{s}}$.

TABLE 2. - COMPUTATIONAL RESULTS

\begin{tabular}{|l|r|l|l|l|l|l|}
\hline Airfoil & $\alpha$ & $\begin{array}{c}\text { Turbulence } \\
\text { model }\end{array}$ & $R_{\mathrm{c}} \times 10^{-3}$ & $M$ & St $_{\mathrm{s}}$ & Reference \\
\hline NACA0012 & 18 & Baldwin-Lomax & 1000 & 0.3 & 0.03 & {$[5]$} \\
NACA0012 & 18 & Laminar & 1000 & 0.3 & 0.16 & {$[5]$} \\
"LRN" & 15 & Baldwin-Lomax & 75 & 0.3 & 0.03 & {$[1]$} \\
Wortmann & 15 & Baldwin-Lomax & 75 & 0.3 & Damped & {$[1]$} \\
"Iced" & 10 & Baldwin-Lomax & 1400 & 0.12 & Damped & Present \\
"Iced" & 10 & MML & 1400 & 0.12 & 0.011 & Present \\
"Iced" & 9 & MML & 100 & 0.10 & Damped & Pnd [3] \\
"Iced" & 9 & Laminar & 100 & 0.10 & 0.008 & Present \\
\hline
\end{tabular}




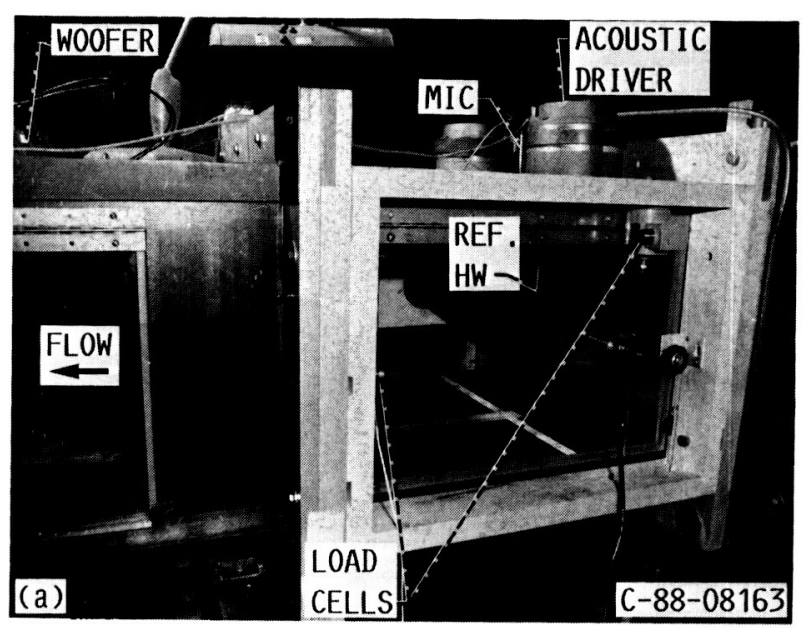

FIGURE 1a. - WIND TUNNEL TEST SECTION.

\section{ORIGANAL PAGE IS \\ OF POOR QUALITY}

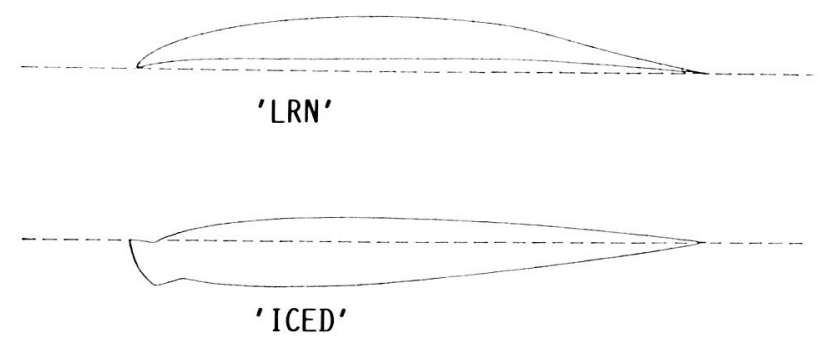

FIGURE 1b. - AIRFOIL CROSS-SECTIONS. UPPER: LRN(1)-1007, LOWER: NACA0012 WITH 'GLAZE ICE ACCRETION'.

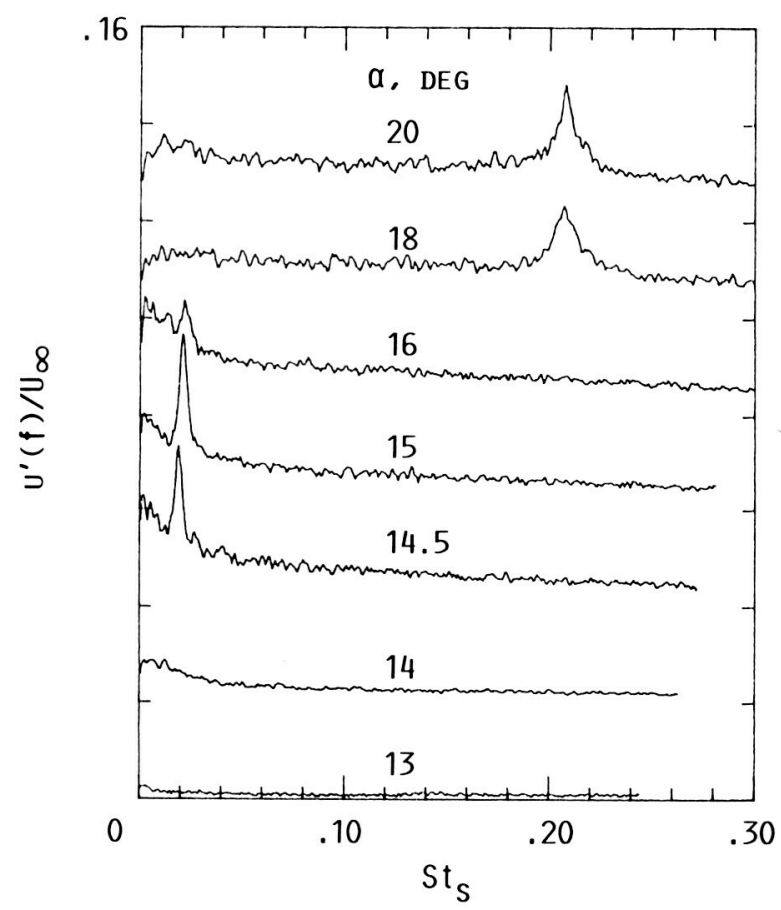

FIGURE 2. - WAKE VELOCITY SPECTRA FOR 'LRN' AIRFOIL. $R_{C}=10^{5}, U_{\infty}^{\prime} / U_{\infty}=$ 0.4 PERCENT; MEASUREMENT AT $\mathrm{X} / \mathrm{C}=1.5$. $y / C=0.15, z=0 . \quad$ SPECTRA TRACES ARE STAGGERED SUCCESSIVELY BY ONE ORDINATE DIVISION. 


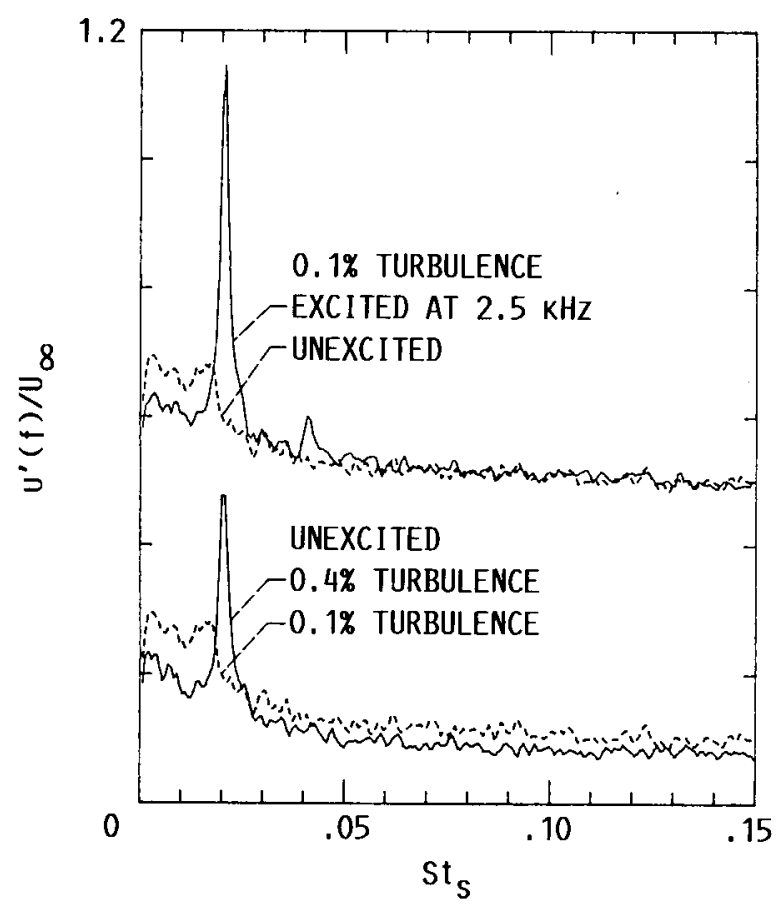

FIGURE 3. - WAKE VELOCITY SPECTRA FOR 'LRN' AIRFOIL AS IN FIGURE 2, SHOWING ENHANCEMENT OF $\mathrm{St}_{\mathrm{S}} \approx 0.02 \mathrm{OSCIL-}$ LATION. $R_{C}=10^{5}, \alpha=15^{\circ}$. UPPER PAIR OF TRACES SHIFTED BY TWO ORDINATE DIVISIONS.

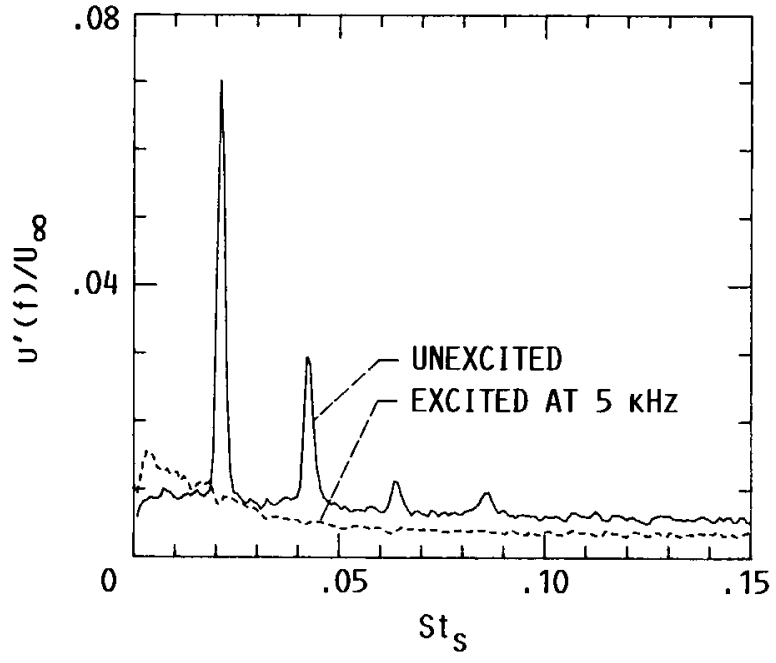

FIGURE 4. - WAKE VELOCITY SPECTRA FOR 'LRN' AIRFOIL AS IN FIGURE 2. SHOWING SUPPRESSION OF $\mathrm{St}_{\mathrm{s}} \approx 0.02$ OSCILLATION. $\mathrm{R}_{\mathrm{C}}=0.75 \times 10^{5}, \alpha=15^{\circ}$. $\mathrm{U}_{\infty}^{\prime} / \mathrm{U}_{\infty}=0.4$ PERCENT.

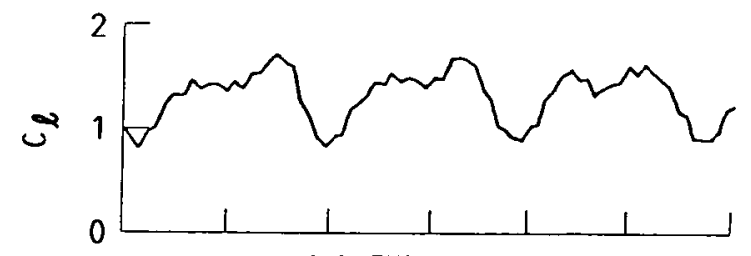

(a) EXPERIMENT.

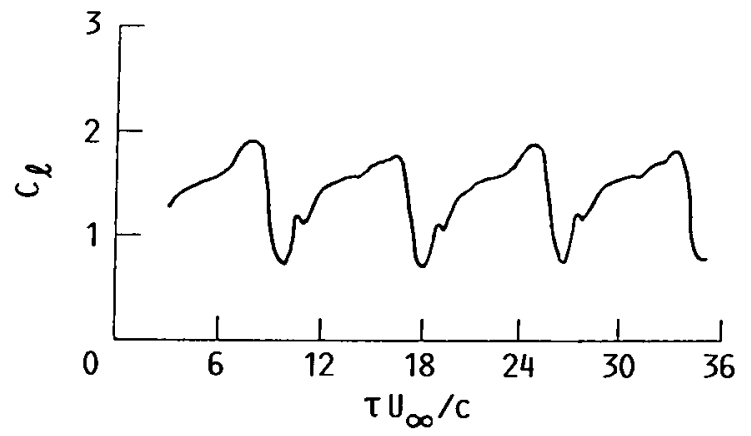

(b) COMPUTATION.

FIGURE 5. - LIFT-COEFFICIENT VARIATION

WITH TIME FOR 'LRN' AIRFOIL AT $\alpha=15^{\circ}$

AND $R_{C}=0.75 \times 10^{5}$. BALDWIN-LOMAX

TURBULENCE MODEL USED IN COMPUTATION. 

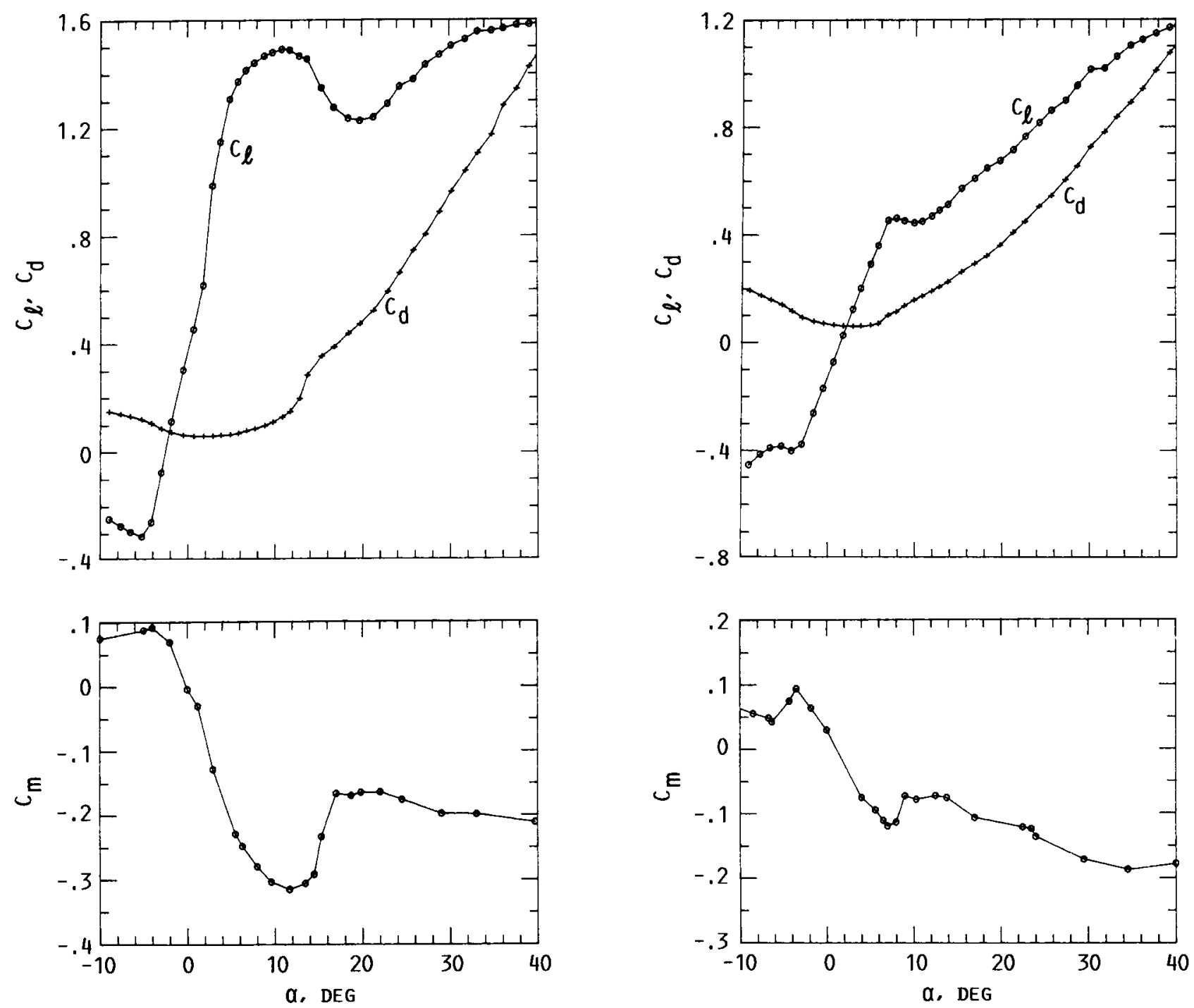

FIGURE 6. $-c_{\ell}, c_{d}$ AND $c_{m}$ VERSUS a FOR THE 'LRN' AIRFOIL. $R_{C}=0.75 \times$ $10^{5}$ AND $U_{\infty}^{\prime} / U_{\infty}=0.4$ PERCENT.

FIgURE 7. $-c_{\ell} \cdot c_{d}$ AND $c_{m}$ VERSUS $a$ FOR THE 'ICED' AIRFOIL. $R_{C}=$ $0.75 \times 10^{5} \cdot u_{\infty}^{\prime} / U_{\infty}=0.4$ PERCENT. 


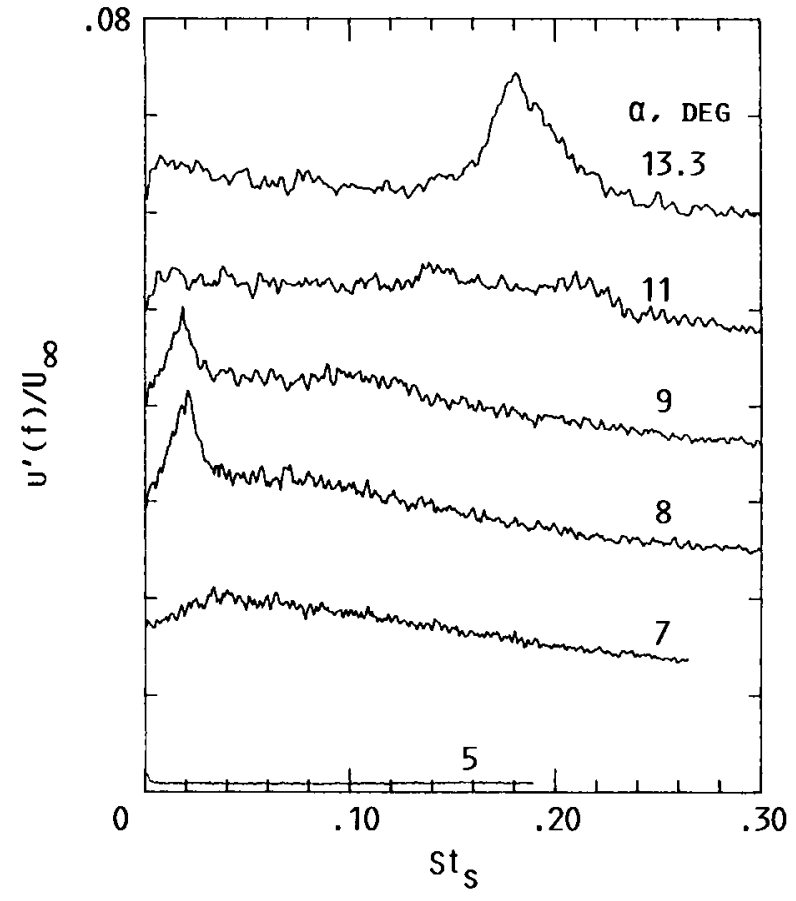

FIGURE 8. - WAKE VELOCITY SPECTRA AS IN FIGURE 2 FOR THE 'ICED' AIRFOIL: $R_{C}$ $=10^{5}$. TRACES ARE STAGGERED BY ONE DIVISION.

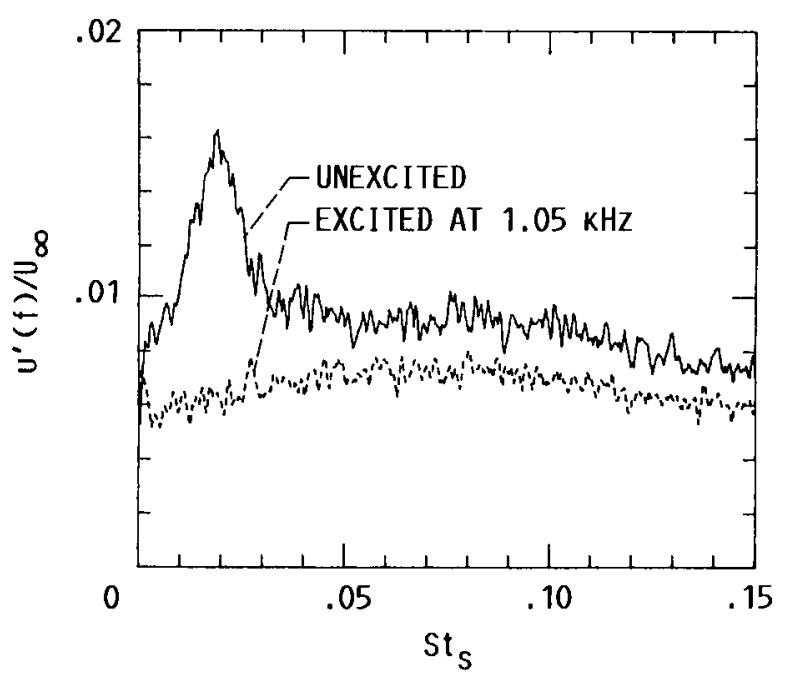

FIGURE 10. - WAKE VELOCITY SPECTRA AS IN FIGURE 4 FOR THE 'ICED' AIRFOIL, SHOWING SUPPRESSION OF $\mathrm{St}_{\mathrm{s}} \approx 0.02$ OSCILLATION. $a=8.5^{\circ}, R_{c}=10^{5}$.

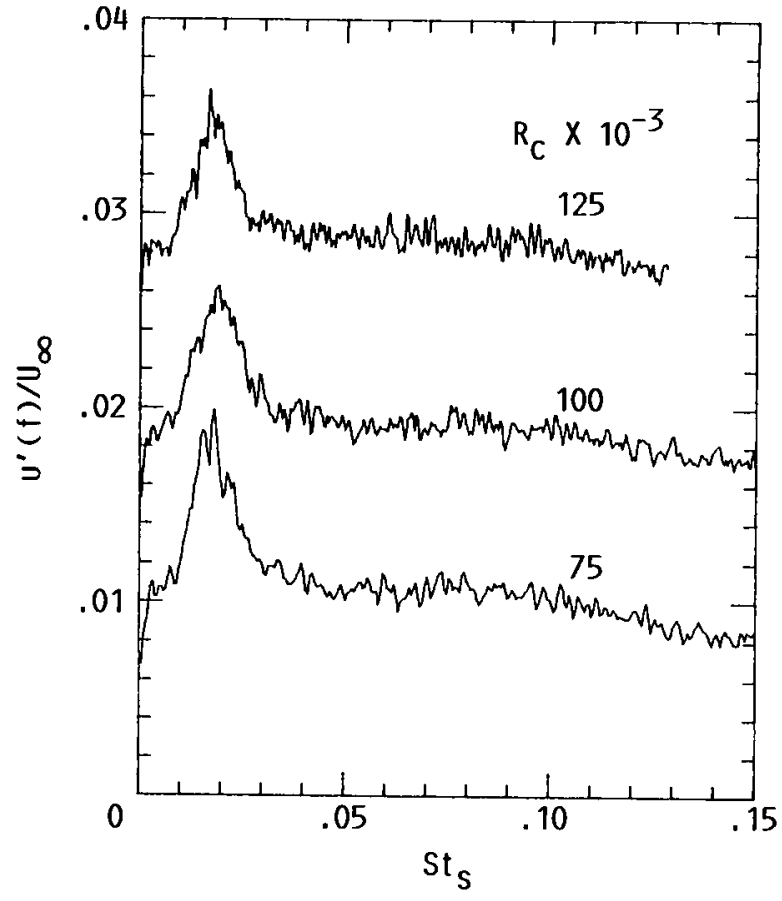

FIGURE 9. - WAKE VELOCITY SPECTRA AS IN FIGURE 2 FOR THE 'ICED' AIRFOIL AT $a=8.5^{\circ}$ FOR INDICATED $R_{C}$. TRACES ARE STAGGERED BY ONE MAJOR DIVISION.
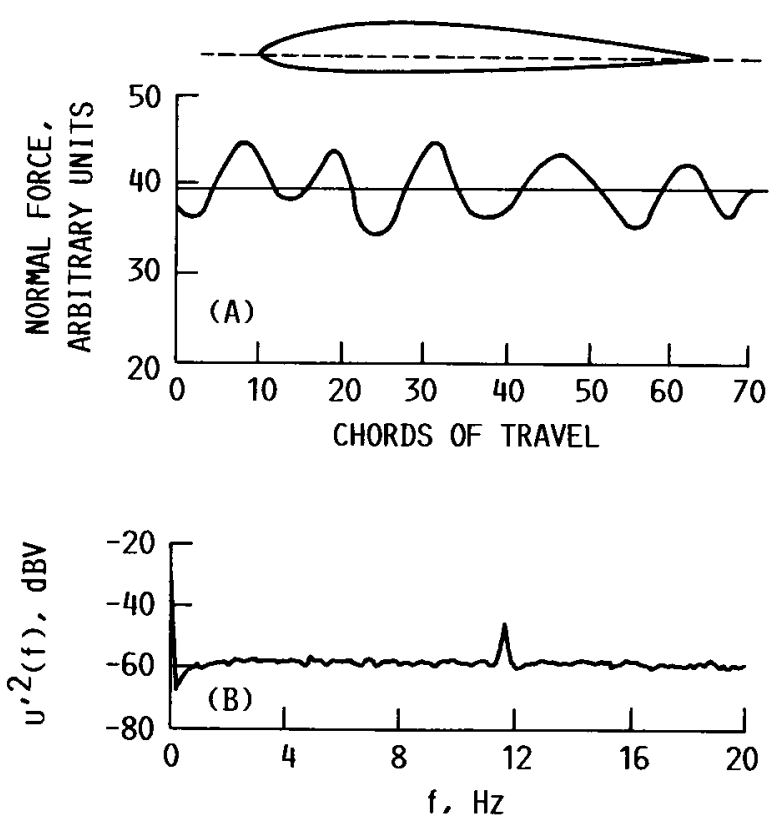

FIGURE 11. - (A) NORMAL FORCE VARIATION FOR R.A.F. 28 AIRFOIL AT $a=14^{0}$ AND $R_{C}=10^{5}$ FROM REF. [6]. (B) VELOCITY SPECTRA MEASURED SHORTLY DOWNSTREAM OF THE 'HORN' OF AN 'ICED' AIRFOIL AT $\alpha \approx 6^{\circ}$ AND $R_{C}=$ $1.5 \times 10^{6}$ FROM REF. [7]. 


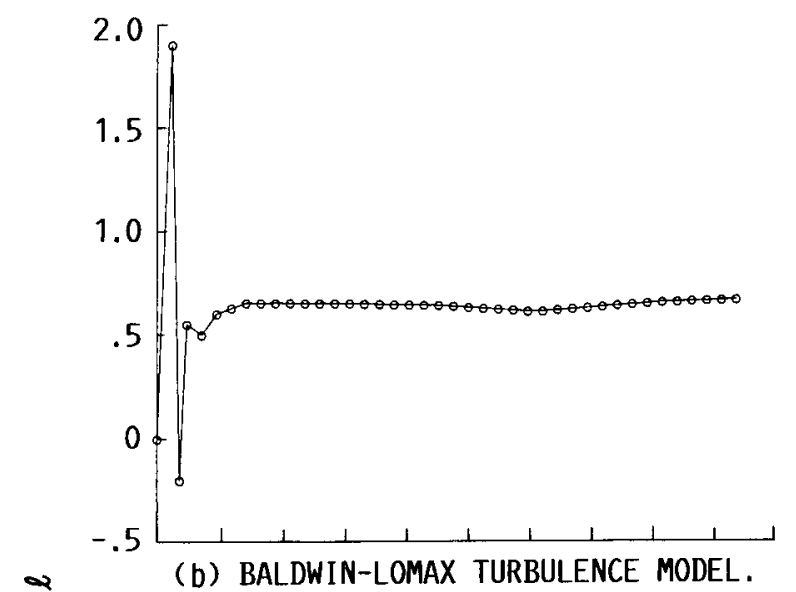

$v^{2}$

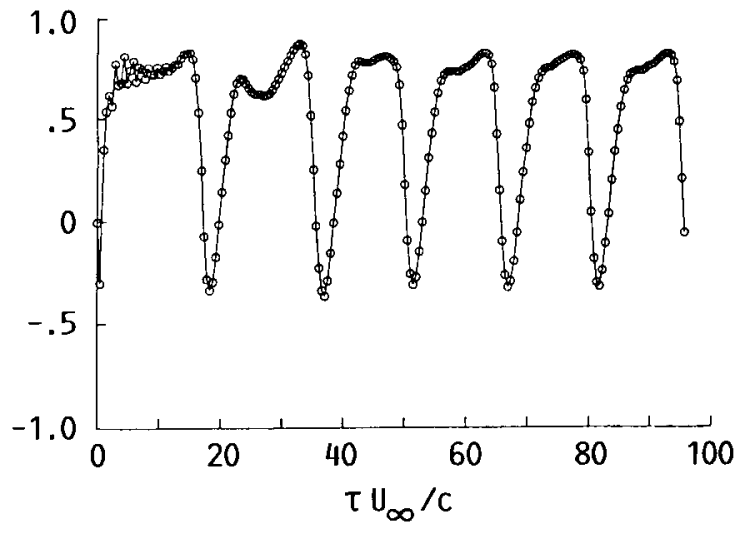

(a) "MML" TURBULENCE MODEL.

FIGURE 12. - COMPUTED LIFT-COEFFICIENT VARIATIONS WITH TIME FOR THE 'ICED' AIRFOIL AT A HIGHER $R_{C} \cdot R_{C}=1.4 \mathrm{x}$ $10^{6}, M=0.12, \alpha=10^{\circ}$.

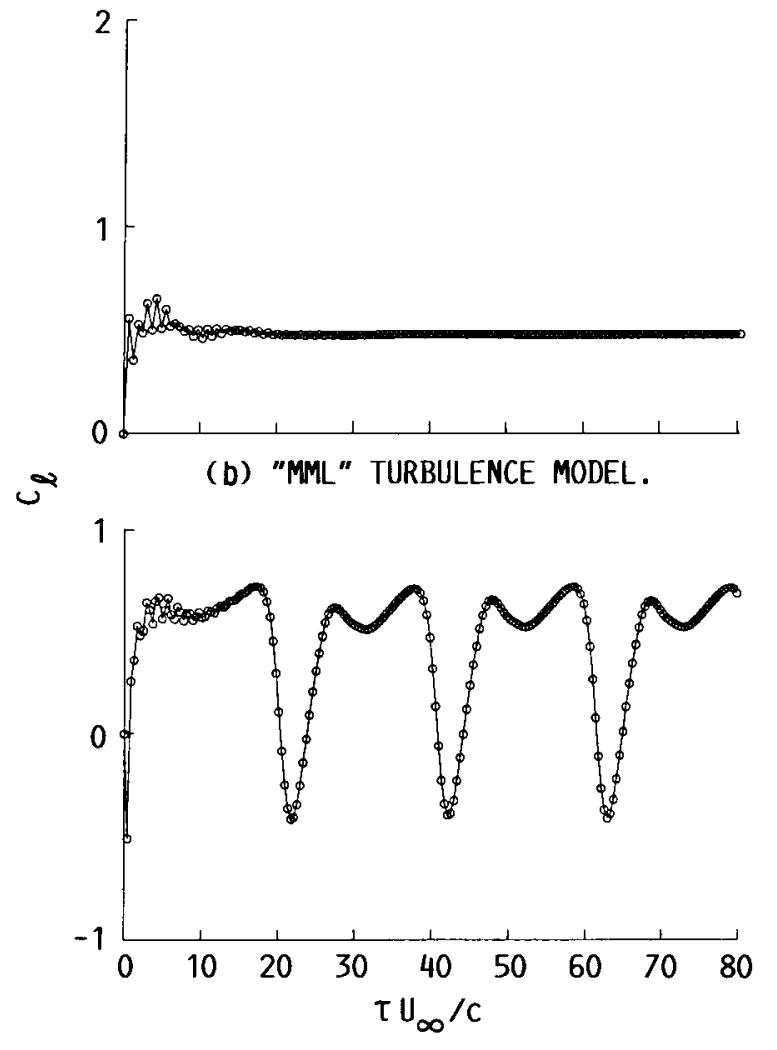

(a) LAMINAR FLOW.

FIGURE 13. - COMPUTED LIFT-COEFFICIENT VARIATIONS WITH TIME FOR THE 'ICED' AIRFOIL AT THE $R_{C F}$ COVERED IN THE EXPERIMENT. $R_{C}=10^{5}, M=0.1, \alpha=9^{0}$. 


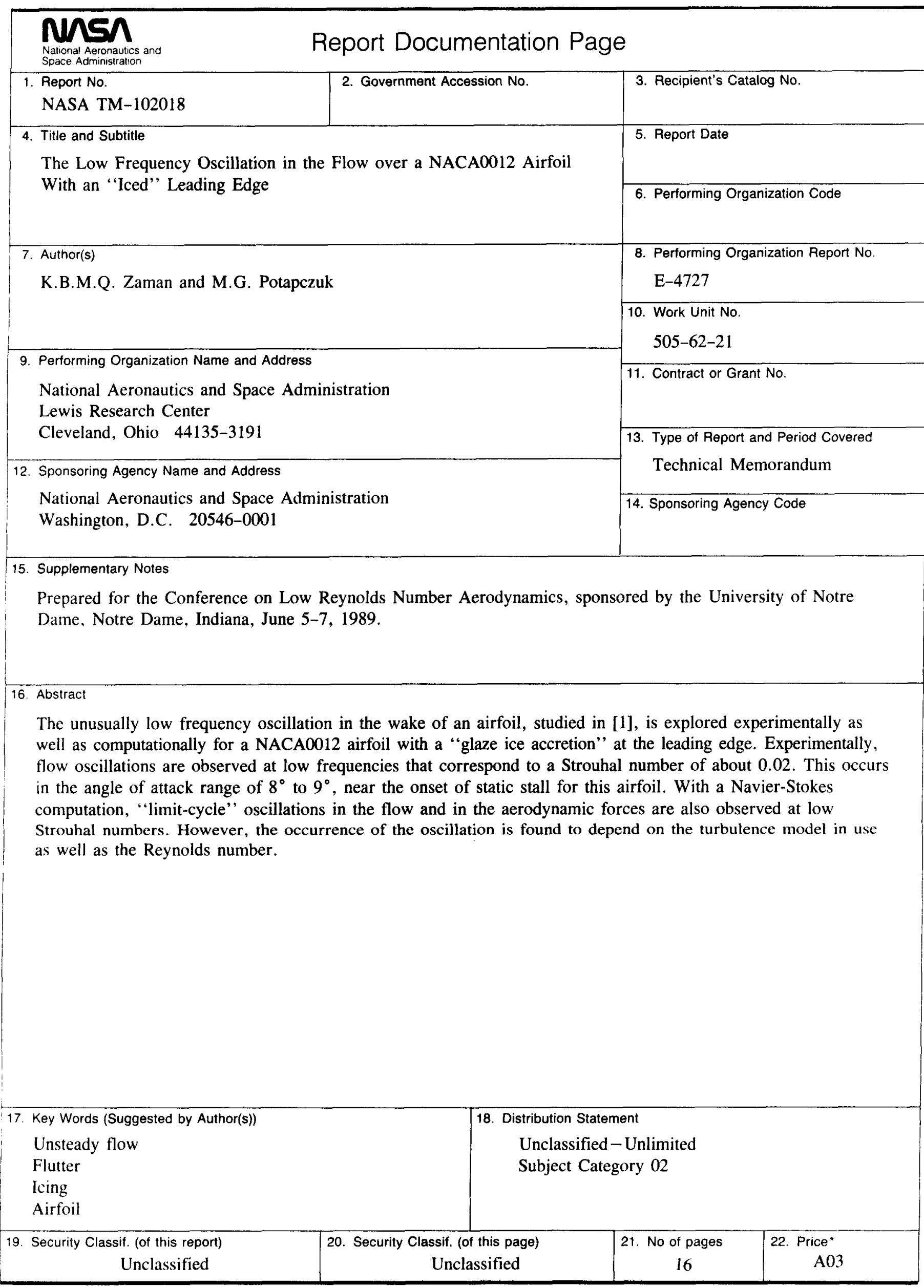

